\author{
Asian Journal of \\ Medical and Biological Research \\ ISSN 2411-4472 (Print) 2412-5571 (Online) \\ www.ebupress.com/journal/ajmbr
}

\title{
Article \\ Management and treatment patterns of diabetes patients having blood pressure complications living in Dhaka city, Bangladesh
}

\author{
A. H. M. Mahmudur Rahman, Lutful Haque Saran, Md. Mamun-Ur-Rashid and Adnan Taher \\ Department of Pharmaceutical Sciences, North South University, Bashundhara, Dhaka-1229, Bangladesh \\ ${ }^{*}$ Corresponding author: A. H. M. Mahmudur Rahman, Department of Pharmaceutical Sciences, North South \\ University, Bashundhara, Dhaka-1229, Bangladesh. Phone: +8801940359764; E-mail: \\ mahmudurrahman51@yahoo.com
}

Received: 07 September 2016/Accepted: 22 September 2016/ Published: 29 September 2016

\begin{abstract}
A study way carried out in Dhaka city to find out the management and treatment patterns of diabetic patients those having blood pressure complications. It was a cross sectional study of 150 patients by using self administered survey questionnaire and founded data was analyzed and described. In this study, it is found that almost all of the patients (92\%) were from Dhaka and just were a few those were outsider but came as referred patients. The male and female percentages were accordingly $64.67 \%$ and $35.33 \%$ and among those diabetes patients $47.33 \%$ had hypertension and $10.66 \%$ had hypotension and most of them (74\%) check their diabetes monthly. Among those patients $79.33 \%$ patients were prescribed only drugs while $17 \%$ patients were prescribed to change their routine only and $4 \%$ were prescribed both (drug and routine). Most of the diabetes patients having blood pressure complicacy were prescribed only drugs which is very significant and those are going to do further research in this aspect will be benefited by getting this information.
\end{abstract}

Keywords: diabetes patients; management; treatment patterns; hypertension; hypotension; Dhaka city

\section{Introduction}

Diabetes is basically a disarray of the metabolism causing excessive thirst and the production of huge amounts of urine. Over the past two decades the pervasiveness of diagnosed diabetes encompasses more than doubled. Though only focusing on glucose alone does not offer sufficient treatment for diabetes patients with other complication like blood pressure complication (the pressure of the blood in the circulatory system is not properly working) which is called either hypertension or hypotension. Lowering destructive glucose level may not be always the best approach in all (Lawson et al., 1999). It is very much recommended for stratification of individual risk to improve the overall conditions of patients (Zimmerman et al., 1998).

Evaluation of blood glucose logs ought to be part of management preparation for any diabetes. For example, both iron and erythropoietin treatments generally prescribed in diabetes patients with persistent kidney disease as without affecting blood glucose levels (Colayco et al., 2011). Because of being a chronic illness it requires patient self-management schooling and ongoing medical care to prevent severe complications and by doing this can reduce the risk of long-term snags. It is known that diabetes care is very complex and requires that numerous issues, further than be addressed. For improving diabetes upshots a large body of data exists that supports a range of intrusions (Engelgau et al., 2000). These cares are intended to offer clinicians and researchers and other involved persons with the workings of diabetes care to tackle to evaluate the quality of care and treatment goals. Because of personage preferences and other co-morbidities, it may be necessitated modification of goals; as are desirable for most patients having diabetes (Gerstein et al., 2011). These values are not planned to rule out more widespread assessment and management of the patient by other professionals.

Usually patients with type-1 diabetes present with severe symptoms of diabetes and noticeably eminent blood glucose levels while patients with type-2 diabetes are habitually not diagnosed until complications come into view and various studies reveal that just about one-third of all people with diabetes may be undiagnosed 
globally. A physician-coordinated squad; such squad may comprise but are not partial to physicians, nurses, pharmacists, dietitians and mental health professionals with a special interest in diabetes are needed to provide medical care and it is vital to joint and incorporated team approach (Jovanovic et al., 2000). And those having blood pressure complications beside diabetes need special care as diabetes and complications both are life threatening for patients.

The management diagram should be devised as an individualized therapeutic alliance among not only the patients and family but also the other members of the health care team. Whichever plan should be familiar with diabetes self-management schooling as an integral constituent of care. In emergent the plan, deliberation should be given to not only the patient's age and conditions and work schedule (NG et al., 2010) but also physical goings-on (Pan et al., 1997) eating outline and existence of complications of diabetes and other medical situation and most importantly controlling blood pressure.

In Bangladesh, diabetes is one of the leading health problems nowadays. It is becoming more challenging to manage and offer appropriate treatments to the people those are suffering from diabetes and blood pressure complications particularly the most populous city, Dhaka. There was lot of research completed basically on pharmacology but there is no significant research on treatment and management of diabetes in this country specially those having blood pressure complications. This is because the study was conducted and it was basically focused on managing and treatment patterns of diabetes patients especially those had blood pressure complications.

\section{Materials and Methods}

It was a cross sectional study and was carried out at outdoor of BIRDEM General Hospital and outdoor of BIHS General Hospital in Dhaka City. The study was conducted from September 2015 to March 2016. The interviews of patients were carried out by previously made well structured and self-administered questionnaire (Annexure 1) and the questionnaire required patient responses and before using the questionnaire in the study, it was tried on some patients to check whether they were able to understand and response. As it was a voluntary participation, those felt interested participated in the survey. Data were collected through survey sheets and then transferred into the Microsoft Excel Spreadsheet 2010 (Microsoft Corp., USA). The analysis was done using SPSS software version 16. The statistical analysis and graphical presentations were performed. Representation of the data was performed as percentage, frequency, mean, and ratio.

Annexure 1

SURVEY QUESTION:

$>$ Name:

$>$ Age:

$>$ Gender:

$>$ Occupation:

$>$ Address:

$>$ Suffering from diabetes (duration) :

$>$ Frequency of check up:

$>$ Current blood pressure:

$>$ Types of treatment:
a) Drug
b) routine
c) Drug+routine both

If drug, which type of drugs?

a) oral tables b) insulin

\section{Results and Discussion}

The total number of patients was $150(\mathrm{n}=150)$. It is initiated that $92 \%$ patients were from Dhaka and only $8 \%$ were from outside of Dhaka as they are referred from all over Bangladesh. In this study group 64.67\% ( $\mathrm{n}=97$ ) were male and $35.33 \%(\mathrm{n}=53)$ were female and $1.8: 1$ is male-female ratio. Among these patients, $15.33 \%$ male and $12 \%$ female were 50-59 age range which is highest among all and after that range, $10.67 \%$ male and $8.67 \%$ female were 40-49 age range and so on (Figure 1). It is also noted that 42.7 and 38.2 were the mean ages of male and female accordingly (Figure 2). If we consider about their occupation, 28\% were businessman, 13.33\% were service holder, and $18 \%$ were retired and $30.67 \%$ were housewife, $1.3 \%$ were in teaching profession and $8.6 \%$ did not feel interest to share (Figure 3). 


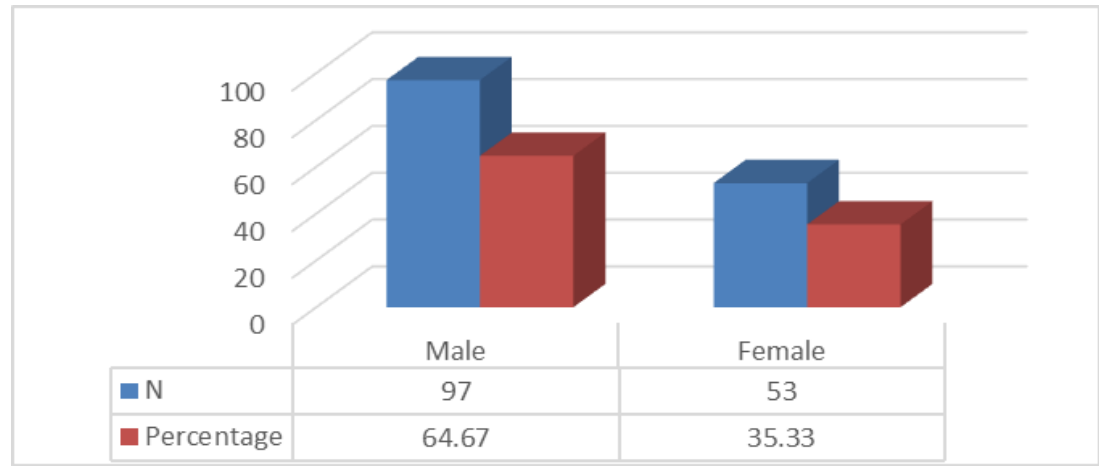

Figure 1. Gender Ratio of diabetes patients.

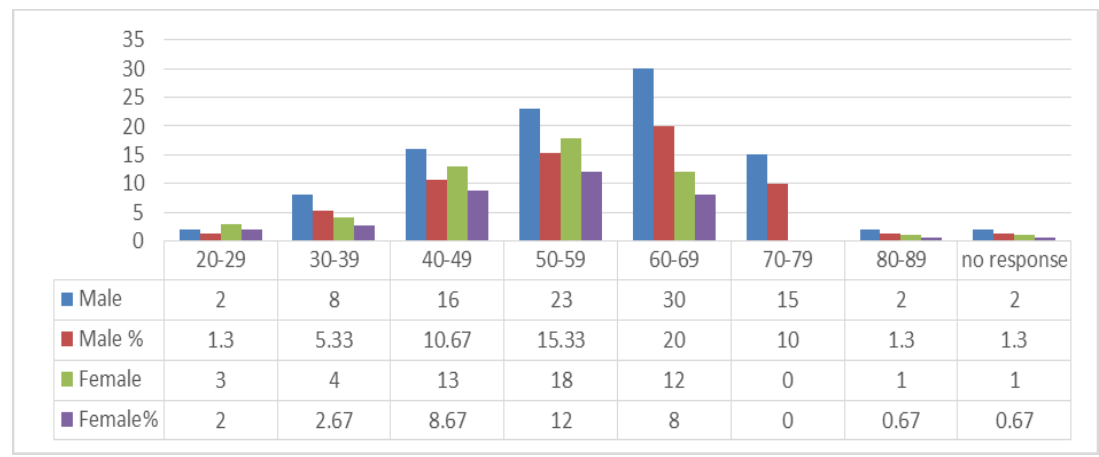

Figure 2. Age range of diabetes patients.

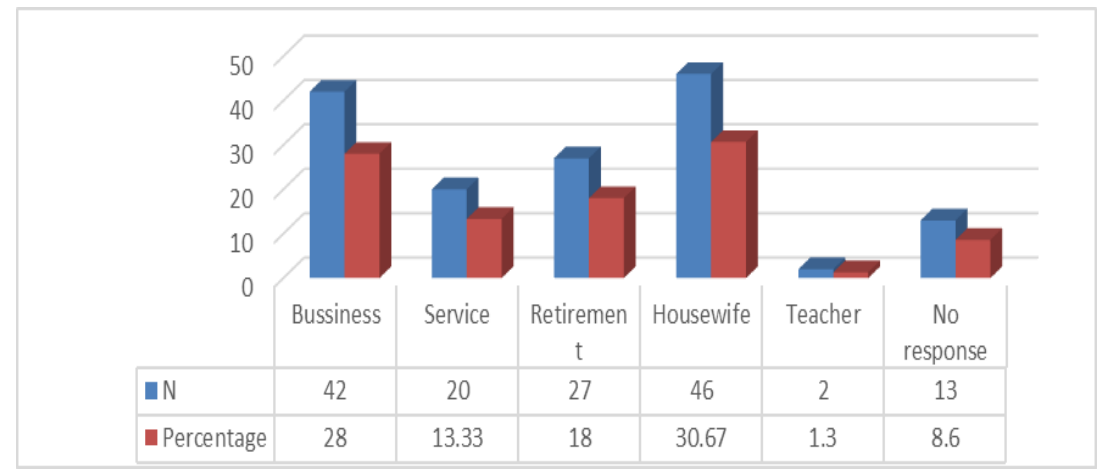

Figure 3. Occupation types of diabetes patients.

Among these diabetes patients, $47.33 \%$ patients had hypertension and $10.66 \%$ patients have hypotension and there were some patients found they were aware about their blood pressure (Figure 4). If we try to correlate between occupation and blood pressure complication, housewife and those were performing business had most percentage of blood pressure complicacy in this study group (Figure 5). There were a few numbers of patients in this study faction, their current blood pressure conditions were normal in range.

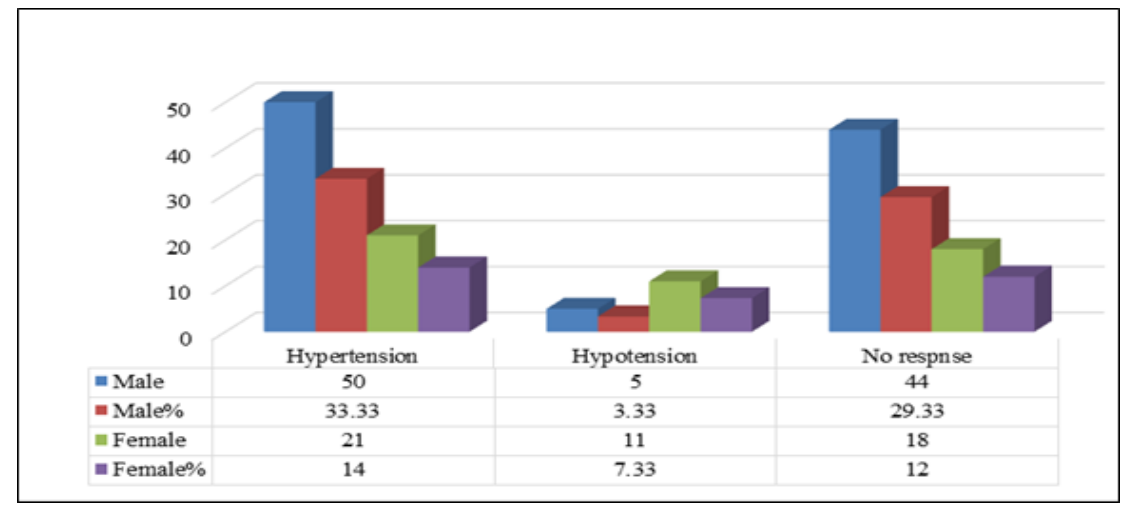

Figure 4. Diabetes patients having hypertension or hypotension. 


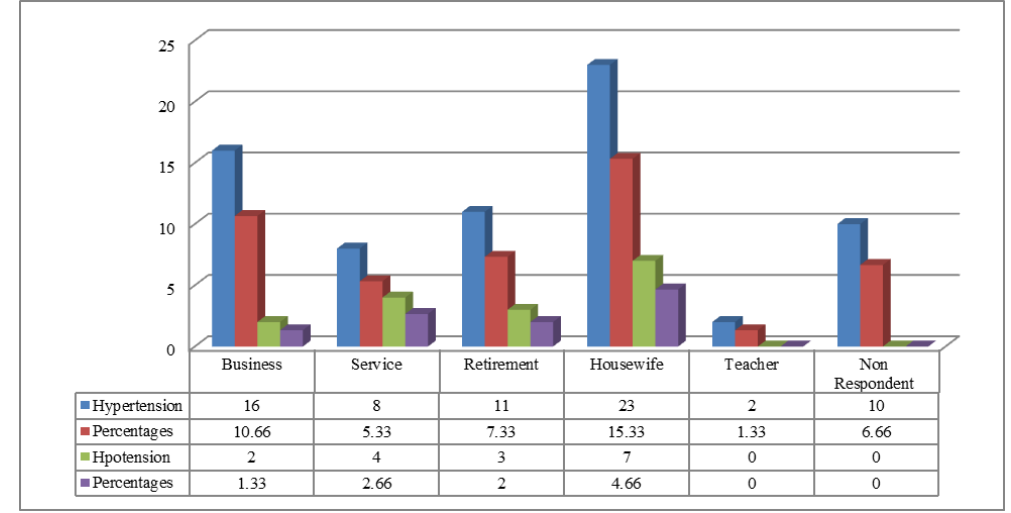

Figure 5. Occupation of diabetes patients with BP complication.

If we consider some major managing aspects duration of diabetes and frequency of check up comes first. In this study it is found that, 7\% patients are suffering from diabetes less than 1 year while $41 \%$ from 1-5 years, $18 \%$ from 6-10 years and 34\% from more than 10 years. Their frequencies of check up are accordingly given: $9 \%$ daily, $15 \%$ weekly, $74 \%$ monthly, and $2 \%$ yearly (Figure 6 ).

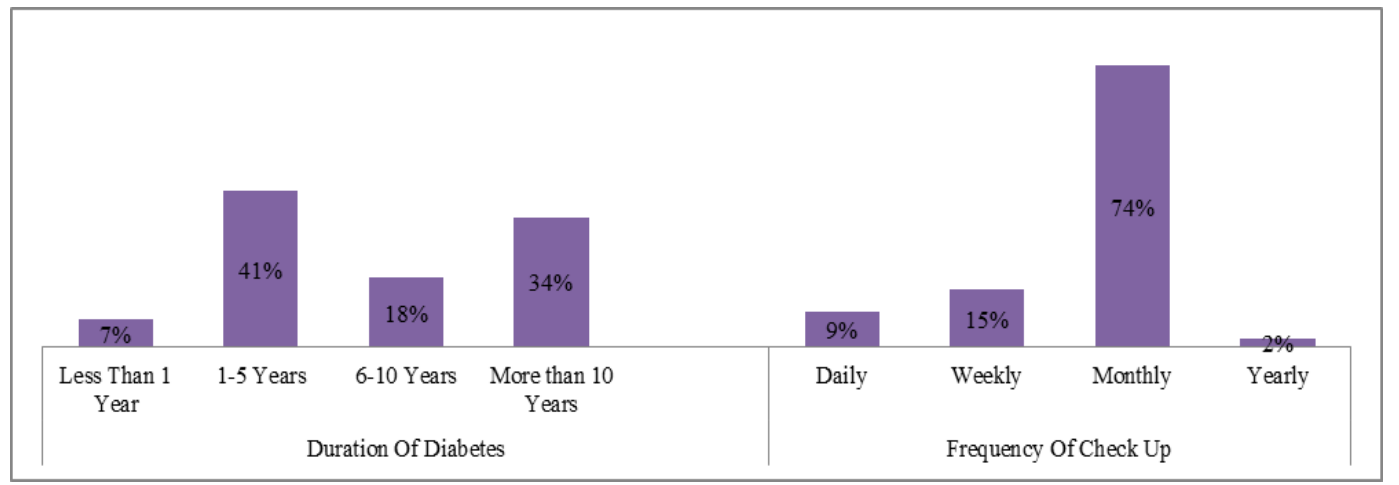

Figure 6. Key managing factors of diabetes mellitus.

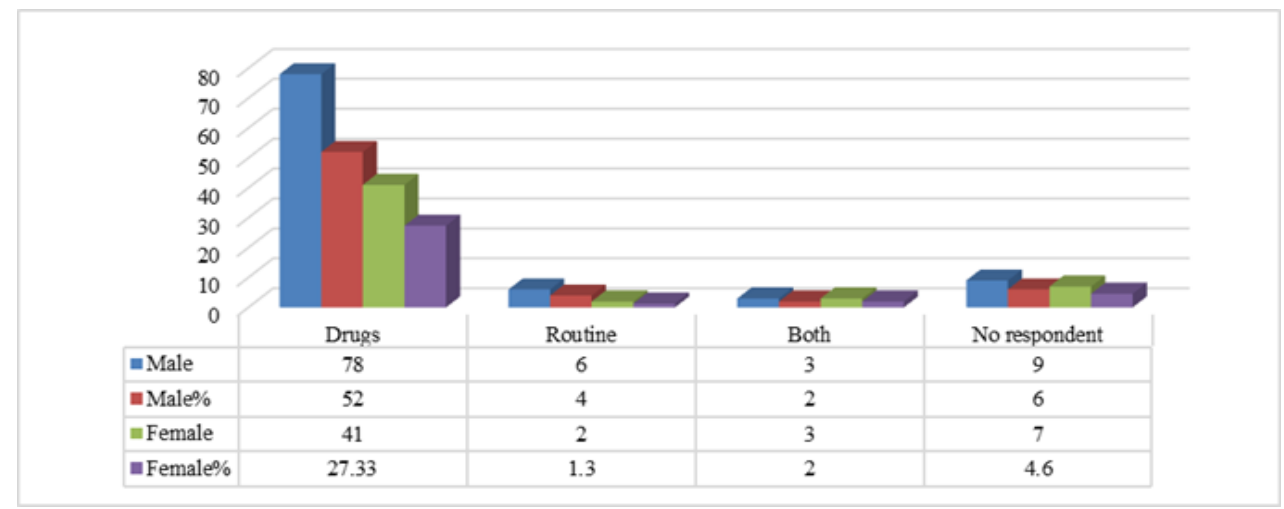

Figure 7. Types of treatments provided to the diabetes patients.

It is found that, $79.33 \%$ patients were prescribed only drugs which is most in percentage despite the fact that $17 \%$ patients were prescribed to change their routine and a few patients $(4 \%)$ were prescribed both (drug and routine) and there were some patients not having clear concept about their treatment those were considered no responses (Figure 7). It is also perceptible that most of prescribed drugs were insulin and very few amounts were oral tablets. Among those tablets there were not only for diabetes but also for other diseases including hypertension and hypotension. It is proved that there is a brawny epidemiological association between hypertension in diabetes and adverse results of diabetes.

The result shows the basic treatment or medication patterns of diabetes patients those having blood pressure complication. Hypertension is an enormously frequent comorbid condition in diabetes, affecting around $20 \%$ to $60 \%$ of patients with diabetes, depending on obesity and age and so on (American Diabetes Association et al., 
2000; American Diabetes Association et al., 2001; American Diabetes Association et al., 2003). It is found in various researches that dietary administration with rational sodium restriction has been effectual in reducing blood pressure in individuals with crucial hypertension (Skyler et al., 1998). Several controlled studies have looked at the association among weight loss and blood pressure decrease. Weight decrease can lessen blood pressure self-governing of sodium intake and in addition can advance blood glucose and also lipid levels (Stratton et al., 2000).

It is very obvious that lots of people will need three or additional drugs to achieve the recommended objective. Accomplishment of the target blood pressure aim with a course of therapy that does not construct burdensome side effects as well as is at reasonable cost to the patient is almost certainly additional important than the exact drug strategy (Tuomilehto et al., 2001). Blood pressure ought to be measured at each routine diabetes rendezvous.

\section{Conclusions}

The study reveals that, most of the patients were from Dhaka and only a few were from outside of Dhaka and they were referred. We can make a conclusion that, most number of the patients were prescribed no more than drugs while few patients were prescribed to change their routine only and an incredibly few (Only 4\%) were prescribed both (drug and routine). As it was not a deep research, further research should be done in this aspect and this information of this study will be very helpful.

\section{Acknowledgements}

We would like to thank those patients for providing their treatment information and the staffs of BIRDEM General Hospital and BIHS General Hospital for their cooperation.

\section{Conflict of interest}

None to declare.

\section{References}

American Diabetes Association, 2001. Postprandial blood glucose (Consensus Statement). Diabetes Care, 24:775-778.

American Diabetes Association, 2000. Type 2 diabetes in children and adolescents (Consensus Statement). Diabetes Care, 23:381-389.

American Diabetes Association, 2003. Gestational diabetes mellitus (Position Statement), Diabetes Care, 26(Suppl. 1): S103-S105.

Colayco DC, F Niu, JS McCombs and TC Cheetham, 2011. A1C and cardiovascular outcomes in type 2 diabetes: a nested case-control study. Diabetes Care, 34:77-83.

DCCT/EDIC Research Group, 2000. Retinopathy and nephropathy in patients with type 1 diabetes four years after a trial of intensive therapy. N. Engl. J. Med., 342: 381-389.

Expert Committee on the Diagnosis and Classification of Diabetes Mellitus, 2003. Report of the Expert Committee on the Diagnosis and Classification of Diabetes Mellitus. Diabetes Care, 26(SUPPL. 1): S5-S20.

Engelgau ME, KMV Narayan and WH Herman, 2000. Screening for type 2 diabetes (Technical Review). Diabetes Care, 23:1563-1580.

Gerstein HC, ME Miller, S Genuth, F Ismail-Beigi, JB Buse, DC Jr Goff, et al., 2011. Long-term effects of intensive glucose lowering on cardiovascular outcomes. N. Engl. J. Med., 364: 818-828.

Jovanovic L (Ed.), 2000. Medical Management of Pregnancy Complicated by Diabetes, 3rd ed. Alexandria, VA, American Diabetes Association.

Lawson ML, HC Gerstein, E Tsui and B Zinman, 1999. Effect of intensive therapy on early macrovascular disease in young individuals with type 1 diabetes, Diabetes Care, 22(Suppl. 1): B35-B39.

National Center for Health Statistics, 2012. National Center for Chronic Disease Prevention and Health Promotion, ed. Crude and age-adjusted percentage of civilian noninstitutionalized adults with diagnosed diabetes, United States, 1980-2010. Atlanta, GA: Centers for Disease Control and Prevention, Division of Diabetes Translation.

Ng JM, M Cooke, S Bhandari, SL Atkin and ES Kilpatrick, 2010. The effect of iron and erythropoietin treatment on the A1C of patients with diabetes and chronic kidney disease. Diabetes Care, 33:2310-2313.

Pan XR, GW Li, YH Hu, JX Wang, WY Yang, ZX An, ZX Hu, J Lin, JZ Xiao, HB Cao, PA Liu, XG Jiang, YY Jiang, JP Wang, H Zheng, H Zhang, PH Bennett and BV Howard, 1997. Effects of diet and exercise in 
preventing NIDDM in people with impaired glucose tolerance: the DaQing IGT and Diabetes Study. Diabetes Care, 20:537-544.

Skyler JS (Ed.), 1998. Medical Management of Type 1 Diabetes, 3rd ed. Alexandria, VA, American Diabetes Association.

Stratton IM, AI Adler, HA Neil, DR Matthews, SE Manley, CA Cull, D Hadden, RC Turner and RR Holman, 2000. Association of glycaemia with macrovascular and microvascular complications of type 2 diabetes (UKPDS 35): prospective observational study. BMJ, 321:405-412.

Tuomilehto J, J Lindstrom, JG Eriksson, TT Valle, H Hamalainen, P Ilanne-Parikka, S Keinanen-Kiukaaniemi, M Laakso, A Louheranta, M Rastas, V Salminen and M Uusitupa, 2001. Prevention of type 2 diabetes mellitus by changes in lifestyle among subjects with impaired glucose tolerance. N. Engl. J. Med., 344:13431350.

The Diabetes Control and Complications Trial Research Group, 1993. Diabetes Control and Complications Trial Research Group: The effect of intensive treatment of diabetes on the development and progression of long-term complications in insulin-dependent diabetes mellitus. N. Engl. J. Med., 329: 977-986.

UK Prospective Diabetes Study Group, 1998. Intensive blood-glucose control with sulphonylureas or insulin compared with conventional treatment and risk of complications in patients with type 2 diabetes (UKPDS 33). Lancet, 352: 837-853.

UK Prospective Diabetes Study (UKPDS) Group, 1998. Effect of intensive blood-glucose control with metformin on complications in overweight patients with type 2 diabetes (UKPDS 34). Lancet, 352:854-865.

Zimmerman BR (Ed.), 1998. Medical Management of Type 2 Diabetes. 4th ed. Alexandria, VA, American Diabetes Association. 